\title{
Preliminary Results of Random Amplification of Polymorphic DNA among Triatominae of the phyllosoma Complex (Hemiptera, Reduviidae)
}

\author{
Simone F Brenière/ ${ }^{+}$, Bruno Taveira, Marie-France Bosseno, Rosalinda Ordoñez*, \\ Felipe Lozano-Kasten**, Ezequiel Magallón-Gastélum**, Ali Ouaissi, Janine Ramsey*
}

Institut de Recherche pour le Développement, UR 008, Pathogénie des Trypanosomatidés, 911 Av. Agropolis, BP 64501, 34394

Montpellier Cedex 1, France *Centro de Investigaciones de Enfermedades Infecciosas, Instituto Nacional de Salud Pública,

Cuernavaca, Morelos, México **Centro Universitario de Ciencias de la Salud, Universidad de Guadalajara, Jalisco, México

In Mexico, Triatoma longipennis (Usinger), Triatoma picturata (Usinger), and Triatoma pallidipennis (Stal), primary Chagas disease vector species of the phyllosoma complex, were analyzed by randomly amplified polymorphic DNA (RAPD). Sixteen decametric primers resolved individual profiles not identical, but partially discriminative between species. Analysis based on pairwise presencelabsence comparisons between the three species was performed using three primers and two outgroup species Triatoma infestans (Klug) and Triatoma barberi (Usinger). Fifty-three bands in total were scored, although only two bands were constant among the three phyllosoma complex species. Two other bands were constant only for $\mathrm{T}$. longipennis and $\mathrm{T}$. picturata together, and not present in $\mathrm{T}$. pallidipennis. Neighbor Joining tree and the multiple correspondence analysis discriminated T. pallidipennis clearly from the other two species, although there was overlap between $\mathrm{T}$. longipennis and $\mathrm{T}$. picturata. The results indicate a close relationship between the studied species and support the hypothesis of their recent evolution. The suitability of RAPD to discern populations within the species is discussed.

Key words: Triatominae - phyllosoma complex - random amplification of polymorphic DNA - phylogeny - Mexico

In Mexico, all primary vectors of the 18 species of Triatominae (Hemiptera: Reduviidae) commonly found infected by Trypanosoma cruzi can be collected inside human dwellings, as well as from peridomestic and sylvatic areas (Zarate \& Zarate 1985, Velasco-Castrejón \& Guzmán-Bracho 1986, Guzmán-Bracho 2001, Ramsey et al. 2000). In view of the recent decision to initiate triatomine control in certain regions of Mexico, short and long-term control strategies for these species would benefit from a better understanding of the relationships between sylvatic and domestic populations of primary vector species.

All 137 species classified within the subfamilly Triatominae, of which 28 are known to occur in Mexico, are currently identified on the basis of morphological criteria (including male genitalia), as well as behavioral and ecological characteristics (Lent \& Wygodzinsky 1979, Galvão et al. 2003). Morphological similarities among species are the basic taxonomic criteria for the main North American species complexes: protracta and phyllosoma. However, species and/or subspecies assignment for members of the complex remains controversial, probably due to the recent evolution of these species groups (Bargues et al. 2000). Preliminary reports regarding the hybridiza-

Financial support: IRD

${ }^{+}$Corresponding author. Fax: +33-04-67-41.6330. E-mail: breniere@mpl.ird.fr

Received 24 June 2003

Accepted 26 November 2003 tion between species (Mazzotti \& Osorio 1942, Ryckman 1962) have confused the recognition of distinct or subspecific members (Lent \& Wygodzinsky 1979).

The phyllosoma complex includes several species, five of which are of key epidemiological importance for Chagas disease transmission in Mexico: Triatoma longipennis (Usinger), Triatoma mazzottii (Usinger), Triatoma pallidipennis (Stal), Triatoma phyllosoma (Burmeister), and Triatoma picturata (Usinger). Differentiation between adult specimens from different species within the complex is feasible based on morphological characteristics, although differentiation between nymphs is not. Despite ample collection records for some of these species, relatively little information is available regarding the ecological niche for each (Ramsey et al. 2000), although they are all exclusively found in the xeric coastal and high plains areas of the Pacific coast of Mexico. Nonetheless, the phylogenetic and taxonomic structure of the phyllosoma complex has received attention recently, with several comparative molecular studies conducted to address relationships among epidemiologically relevant species. A multilocus enzyme electrophoresis analysis (MLEE) at 17 putative loci strongly support the grouping of $T$. longipennis, T. pallidipennis, and T. picturata in the same complex, and genetic distances calculated between the three species analyzed were not significantly different from zero (Flores et al. 2001). The sequence comparison of the rDNA second internal transcribed spacer (ITS-2) gene involves two to four nucleotide differences between phyllosoma complex species, or even no differences at all in the case of T. longipennis and T. picturata (Marcilla et al. 2001). More recent studies comparing rLSU and ND4 mitochondrial DNA sequences confirm greater than 5\% 
sequence divergence between $T$. pallidipennis, $T$. phyllosoma, and T. picturata, although similar information for the other members of the complex is not yet available (Harris 2001).

In an effort to analyze molecular markers with different resolving capacity, and since isoenzyme analyses have failed to discriminate major species belonging to the phyllosoma complex, the present study has analyzed random amplification polymorphic DNA (RAPD) profiles for T. longipennis, T. pallidipennis, and T. picturata, three species which are sympatric in limited areas of their distribution ranges.

\section{MATERIALS AND METHODS}

Triatomine bugs - Male and female adults of T. longipennis, T. picturata, and T. pallidipennis were collected following active daytime searches between April 1998 and June 2000 in domestic, peridomestic, and sylvatic areas (Table I). T. barberi (from Oaxaca state, Mexico) and $T$. infestans (from Caranavi province, Bolivia) were used as outgroup species. Taxonomic identifications were determined by morphology according to Lent and Wygodzinsky (1979), and bug specimens were preserved in $70 \%$ ethanol for subsequent DNA extraction from legs.
DNA samples -Two to four legs from each individual were ground to a fine powder in the presence of liquid nitrogen, mixed with $1 \mathrm{ml}$ of lysis buffer, and incubated overnight $\left(37^{\circ} \mathrm{C}\right)$ according to Garcia et al. (1998). DNA was extracted sequentially with phenol, phenol-chloroform-isoamyl alcohol, and chloroform-isoamyl alcohol, and precipitated with ethanol in $0.3 \mathrm{M}$ sodium acetate. DNA concentration and purity were determined by spectrophotometry $(260 \mathrm{~nm}$ and $280 \mathrm{~nm})$. Extracted DNA samples were divided and stored at $-20^{\circ} \mathrm{C}(10 \mu \mathrm{g} / \mathrm{ml})$.

$R A P D$ - The reaction mixture of $60 \mu$ contained the PCR Master Mix 2X (Promega, Madison, WI), $1.2 \mu \mathrm{l}$ primer-10 $\mu \mathrm{M}$, approximately $40 \mathrm{ng}$ template DNA and nuclease free water. Amplifications were performed on a thermal cycler PTC-100 (MJ Research): an initial denaturation step of $1 \mathrm{~min}$ at $94^{\circ} \mathrm{C}$, followed by 45 cycles of $1 \mathrm{~min}$ at $94^{\circ} \mathrm{C}, 1 \mathrm{~min}$ at $36^{\circ} \mathrm{C}, 2 \mathrm{~min}$ at $72^{\circ} \mathrm{C}$, and a final elongation step of $7 \mathrm{~min}$ at $72^{\circ} \mathrm{C}$. The amplification products were separated by electrophoresis in a $1.5 \%$ agarose gel (in TAE) and stained with ethidium bromide. Each amplification included a negative control PCR reaction with DNA free water instead of DNA template. Twenty-two primers were tested: U11, U15, and Opa1 to Opa20 (kit A and U; Operon technology, Alameda, CA).

TABLE I

Species and origin of triatomine bugs (collected in field) used as source of DNA for random amplification of polymorphic DNA analysis

\begin{tabular}{|c|c|c|c|c|c|}
\hline Code & Sex & Species & Country/State & County & Collection sites \\
\hline Nay 16 & M & T. longipennis & Mexico/Nayarit & Tepic & Peridomestic \\
\hline Cari 17 & M & T. longipennis & Mexico/Nayarit & Compostela & Peridomestic \\
\hline Cari 29 & M & T. longipennis & Mexico/Nayarit & Compostela & Peridomestic \\
\hline Cari 50 & M & T. longipennis & Mexico/Nayarit & Compostela & Domestic \\
\hline Cux 46 & M & T. longipennis & Mexico/Zacatecas & Moyahua & Peridomestic \\
\hline Cux 78 & $\mathrm{~F}$ & T. longipennis & Mexico/Zacatecas & Moyahua & Peridomestic \\
\hline Cux 90 & M & T. longipennis & Mexico/Zacatecas & Moyahua & Domestic \\
\hline $\operatorname{Sma} 165^{a}$ & $\mathrm{~F}$ & T. longipennis & Mexico/Jalisco & S.M. Hidalgo & Domestic \\
\hline Sma 168 & $\mathrm{~F}$ & T. longipennis & Mexico/Jalisco & S.M. Hidalgo & Domestic \\
\hline Sma 171 & $\mathrm{~F}$ & T. longipennis & Mexico/Jalisco & S.M. Hidalgo & Domestic \\
\hline Cari $06^{a}$ & M & T. picturata & Mexico/Nayarit & Compostela & Peridomestic \\
\hline Cari 28 & M & T. picturata & Mexico/Nayarit & Compostela & Sylvatic \\
\hline Cari 51 & $\mathrm{~F}$ & T. picturata & Mexico/Nayarit & Compostela & Peridomestic \\
\hline Cari 52 & M & T. picturata & Mexico/Nayarit & Compostela & Peridomestic \\
\hline Cari 80 & M & T. picturata & Mexico/Nayarit & Compostela & Peridomestic \\
\hline Cari 81 & M & T. picturata & Mexico/Nayarit & Compostela & Peridomestic \\
\hline Cari 82 & M & T. picturata & Mexico/Nayarit & Compostela & Peridomestic \\
\hline Cari 141 & $\mathrm{~F}$ & T. picturata & Mexico/Nayarit & Compostela & Sylvatic \\
\hline Cari 142 & $\mathrm{~F}$ & T. picturata & Mexico/Nayarit & Compostela & Sylvatic \\
\hline Cari 143 & M & T. picturata & Mexico/Nayarit & Compostela & Sylvatic \\
\hline 8034 & M & T. pallidipennis & Mexico/Morelos & Jantetelco & Domestic \\
\hline 8098-1 & M & T. pallidipennis & Mexico/Morelos & Jantetelco & Domestic \\
\hline 605302 & $\mathrm{~F}$ & T. pallidipennis & Mexico/Oaxaca & Mariscala de Juarez & Peridomestic \\
\hline 605332 & $\mathrm{~F}$ & T. pallidipennis & Mexico/Oaxaca & Huajuapan & Peridomestic \\
\hline 605333 & $\mathrm{~F}$ & T. pallidipennis & Mexico/Oaxaca & S. M. Amatitlan & Peridomestic \\
\hline $800395^{a}$ & M & T. pallidipennis & Mexico/Morelos & Temixco & Domestic \\
\hline 800401-1 & M & T. pallidipennis & Mexico/Morelos & Cuernavaca & Domestic \\
\hline 800406 & M & T. pallidipennis & Mexico/Morelos & Jiutepec & Domestic \\
\hline 800587-1 & M & T. pallidipennis & Mexico/Morelos & Tlaltizapan & Sylvatic \\
\hline $800641-1$ & M & T. pallidipennis & Mexico/Morelos & Tlaltizapan & Sylvatic \\
\hline Cori 1 & M & T. infestans & Bolivia & Coripata & Domestic \\
\hline Sba 26 & $\mathrm{~F}$ & T. barberi & Mexico/Oaxaca & Sta. Ma.Coyotepec & Peridomestic \\
\hline
\end{tabular}

M: male; F: female; S. M.: San Miguel; Sta. Ma.: Santa Maria; $a$ : samples not included in the pairwise comparison between species 
Data analysis - For each primer, reproducible and clearly identifiable bands were classified according to their relative electrophoresis position. For each sample, a matrix of presence/absence of each band was created. The RAPD Distance Program version 1.04 (available at ftp:// life.anu.edu.au/pub/softward/RAPD Distance or http:// life.anu.edu.au/molecular/software/rapd.html) was used to analyze the RAPD bandings and to depict relationships between the species. Pairwise distances between two samples $\mathrm{x}$ and $\mathrm{y}$ were calculated using the Sneath and Sokal distance applying the square root transformation to the distances measures (individuals characterized by the presence (1) or absence (0) of bands): $(\mathrm{n} 11+\mathrm{n} 00) /$ $\left(\mathrm{n} 11+0.5^{*}(\mathrm{n} 10+\mathrm{n} 01)+\mathrm{n} 00\right.$ with $\mathrm{n} 11=$ the number of position where $\mathrm{x}=1$ and $\mathrm{y}=1, \mathrm{n} 00=$ the number of position where $\mathrm{x}=0$ and $\mathrm{y}=0, \mathrm{n} 01=$ the number of position where $\mathrm{x}=0$ and $\mathrm{y}=1, \mathrm{n} 10=$ the number of position where $\mathrm{x}=1$ and $\mathrm{y}=0$. This distance gives values in the range 0 to +1 . A Neighbor Joining tree was generated from the distance matrix. The multiple correspondence analysis (MCA) was performed using the ADE-4 program (Thioulouse et al. 1997).

\section{RESULTS}

Banding analysis - Discrete RAPD profiles were obtained for 16 of 22 primers tested. The comparison of RAPD profiles among three individuals of each species, $T$. longipennis, T. picturata, and T. pallidipennis resulted in overall profile diversity, but the absence of speciesspecific patterns or bands. T. infestans and T. barberi had multiple bands that were not present in the phyllosoma complex species. In order to analyze the inter and intra species variability, nine individuals of each species were analyzed. For each of the 16 primers, remarkable intraspecies variability was observed, but these patterns were generally complex and required further analysis for pairwise presence/absence comparisons between species (Fig. 1). Comparative pairwise analyses were conducted using three of these primers, selected arbitrarily (Opa 03, Opa 10, and Opa 13). In order to evaluate band reproducibility, a part of the amplifications were repeated twice and in each case the most intense bands were reproducible. Differences in reproducibility were observed in some lowintensity bands, and these were therefore excluded from the comparative analyses. The banding patterns were first compared between individuals of a single species in one gel, and then samples representative of the scored bands for each species were compared on another gel, which included outgroup specimens (T. barberi and T. infestans; Fig. 1). Table II details the observed banding for all species. In total, 53 bands were identified, the number of bands per specimens ranged between 11 and 23 (average15.6 \pm 2.5). Two bands were common to all three phyllosoma complex species (Opa 10-08, Opa 13-10), one of which was also present in T. barberi, while 13 bands were present in only one of the three phyllosoma complex species. The total number of bands and the average number of bands per species were similar independent of the primer used. A total of 40 bands was present in the phyllosoma complex species, while $T$. pallidipennis specimens had more bands (32) than the other two species (25 each). Although

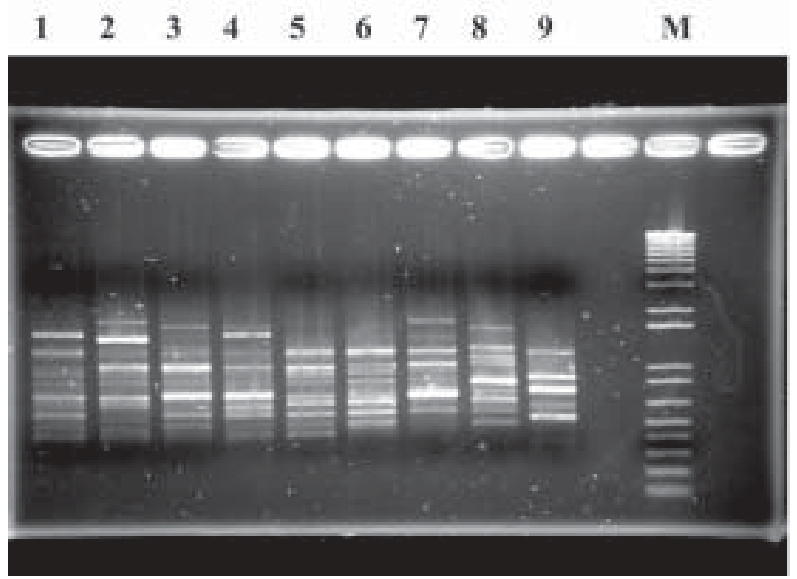

Fig. 1: random amplification of polymorphic DNA profiles for representative banding obtained using Opa3 primer. Agarose gel $(1.5 \%)$ electrophoresis of the different amplified products after ethidium bromide staining. Lanes - 1-3: Triatoma longipennis (Cux90, Sma171, Cux46); 4-6: T. picturata (Cari142, Cari143, Cari141); 7: T. pallidipennis (800401); 8: T. infestans (Cori 1); 9: T. barberi (Sba26); M: molecular Weight (1-kb ladder marker, Gibco)

several bands were common to each species (6 for $T$. longipennis, 7 for T. picturata, and 5 for T. pallidipennis), none was species specific. Only two bands were common to both T. longipennis and T. picturata while absent in $T$. pallidipennis.

Clustering analysis - A Neighbor Joining tree was constructed from the distance matrix joining band data obtained for the three primers independently. T. infestans and T. barberi individuals clustered apart from the phyllosoma complex species and presented a high genetic distance between them (0.52). T. pallidipennis individuals were distributed in several branches but clustered together, separate from T. longipennis and T. picturata, when the tree was built without T. infestans and T. barberi specimens (Fig. 2), while sub-branches also clearly separate T. longipennis from T. picturata.

In order to better assess the relationships between the three species, they were analyzed using multiple correspondences for the presence/absence of the 53 scored bands, and discrimination of the species was tested by the construction of ellipses. The projection of samples in a bi-dimensional graph explained $43 \%$ of the total variability. T. pallidipennis clustered separately from the two other species, while the ellipses for T. longipennis and $T$. picturata overlapped (Fig. 3).

\section{DISCUSSION}

We have obtained RAPD profiles for the majority of the primers tested, using multiple specimens of three species belonging to the phyllosoma complex. Two constant bands (among 40) were common to the three species, while two other bands were common to T. longipennis and $T$. picturata, but absent in T. pallidipennis. However, no species-specific markers were observed. This result is consistent with other morphological and molecular information indicating the recent evolution and close relationship among the phyllosoma complex species. The lack of species-specific RAPD markers is also consistent with 
the lack of morphological criteria differentiating among nymphs of the different species.

Individual sample RAPD profiles were complex, indicating high polymorphism within and between each species over the range of bands observed for the three stud- ied phyllosoma complex species. Relatedness of individuals was estimated by band sharing coefficient and construction of Neighbor Joining tree and by MCA analysis. Although T. pallidipennis bugs were collected from two distinct states (Morelos is in the central part of Mexico

TABLE II

Distribution of the 53 random amplification of polymorphic DNA scored bands among the total sample

\begin{tabular}{|c|c|c|c|c|c|}
\hline \multirow[b]{2}{*}{ Bands } & \multicolumn{3}{|c|}{ Band frequencies } & \multicolumn{2}{|c|}{ Presence (+) / absence (-) } \\
\hline & T. longipennis & T. picturata & T. pallidipennis & T. barberi & T. infestans \\
\hline Opa10-08 & 1.00 & 1.00 & 1.00 & - & - \\
\hline Opa13-10 & 1.00 & 1.00 & 1.00 & + & - \\
\hline Opa3-06 & 1.00 & 1.00 & 0.88 & + & - \\
\hline Opa3-13 & 1.00 & 1.00 & 0.00 & - & - \\
\hline Opa13-17 & 1.00 & 1.00 & 0.00 & - & - \\
\hline Opa3-08 & 1.00 & 0.55 & 0.00 & - & - \\
\hline Opa13-15 & 0.88 & 1.00 & 0.22 & - & - \\
\hline Opa13-08 & 0.88 & 0.88 & 0.77 & - & - \\
\hline Opa10-12 & 0.88 & 0.66 & 0.11 & + & - \\
\hline Opa10-13 & 0.88 & 0.44 & 0.33 & - & - \\
\hline Opa3-18 & 0.88 & 0.22 & 0.00 & - & - \\
\hline Opa13-13 & 0.88 & 0.00 & 0.11 & - & - \\
\hline Opa13-05 & 0.77 & 0.77 & 0.66 & - & - \\
\hline Opa10-15 & 0.77 & 0.77 & 0.22 & - & - \\
\hline Opa13-06 & 0.77 & 0.44 & 1.00 & - & + \\
\hline Opa10-10 & 0.66 & 0.55 & 1.00 & - & - \\
\hline Opa3-14 & 0.55 & 0.55 & 1.00 & - & + \\
\hline Opa10-01 & 0.33 & 0.33 & 0.66 & - & - \\
\hline Opa13-16 & 0.22 & 0.00 & 0.22 & - & + \\
\hline Opa3-04 & 0.22 & 0.00 & 0.00 & - & - \\
\hline Opa10-05 & 0.11 & 0.33 & 0.22 & - & - \\
\hline Opa10-03 & 0.11 & 0.11 & 0.11 & + & + \\
\hline Opa3-03 & 0.11 & 0.11 & 0.00 & - & - \\
\hline Opa3-01 & 0.11 & 0.00 & 0.22 & - & - \\
\hline Opa3-02 & 0.11 & 0.00 & 0.00 & - & + \\
\hline Opa3-15 & 0.00 & 1.00 & 0.55 & - & + \\
\hline Opa13-14 & 0.00 & 0.88 & 0.66 & + & + \\
\hline Opa3-17 & 0.00 & 0.33 & 0.00 & - & + \\
\hline Opa3-09 & 0.00 & 0.22 & 0.66 & - & - \\
\hline Opa10-07 & 0.00 & 0.11 & 0.22 & - & - \\
\hline Opa13-03 & 0.00 & 0.00 & 0.88 & - & - \\
\hline Opa10-06 & 0.00 & 0.00 & 0.55 & - & + \\
\hline Opa13-18 & 0.00 & 0.00 & 0.55 & - & - \\
\hline Opa13-11 & 0.00 & 0.00 & 0.22 & - & + \\
\hline Opa13-12 & 0.00 & 0.00 & 0.22 & + & - \\
\hline Opa3-10 & 0.00 & 0.00 & 0.11 & + & - \\
\hline Opa3-11 & 0.00 & 0.00 & 0.11 & - & + \\
\hline Opa10-04 & 0.00 & 0.00 & 0.11 & + & + \\
\hline Opa10-11 & 0.00 & 0.00 & 0.11 & - & - \\
\hline Opa13-04 & 0.00 & 0.00 & 0.11 & + & + \\
\hline Opa3-05 & 0.00 & 0.00 & 0.00 & - & + \\
\hline Opa3-07 & 0.00 & 0.00 & 0.00 & - & + \\
\hline Opa3-12 & 0.00 & 0.00 & 0.00 & + & - \\
\hline Opa3-16 & 0.00 & 0.00 & 0.00 & + & - \\
\hline Opa10-02 & 0.00 & 0.00 & 0.00 & + & + \\
\hline Opa10-09 & 0.00 & 0.00 & 0.00 & - & + \\
\hline Opa10-14 & 0.00 & 0.00 & 0.00 & - & + \\
\hline Opa10-16 & 0.00 & 0.00 & 0.00 & + & - \\
\hline Opa10-17 & 0.00 & 0.00 & 0.00 & - & + \\
\hline Opa13-01 & 0.00 & 0.00 & 0.00 & - & + \\
\hline Opa13-02 & 0.00 & 0.00 & 0.00 & - & + \\
\hline Opa13-07 & 0.00 & 0.00 & 0.00 & + & + \\
\hline Opa13-09 & 0.00 & 0.00 & 0.00 & - & + \\
\hline
\end{tabular}

T.: Triatoma 
and Oaxaca a more southern region separated from the previous by the Mixtecan Sierra), they were quite easily grouped separately from $T$. longipennis and $T$. picturata populations, independent of the analysis used. However, MCA analysis without the T. barberi and T. infestans outgroups indicated a potential separation of Morelos and Oaxacan T. pallidipennis populations, consistent with recent data using ITS-2 ribosomal DNA markers (MD Bargues, Department of Parasitology, Valencia University, Spain, pers. commun.). Further analysis of a greater number of individuals using the RAPD marker and others, will clarify whether the current polarization of populations implies genetic isolation or distancing due to geographic separation along a continuum.

Individuals of $T$. longipennis and $T$. picturata clustered separately from $T$. pallidipennis, although the separation between $T$. longipennis and $T$. picturata was not complete and had certain overlap. The overlap between the two species was similar whether the outgroups were included or not in the MCA analysis. These data are consistent with the lack of sequence divergence between the two species using the ITS-2 gene (Marcilla et al. 2001).

Neither RAPD analysis, nor other molecular markers, correlates completely with adult morphological differences

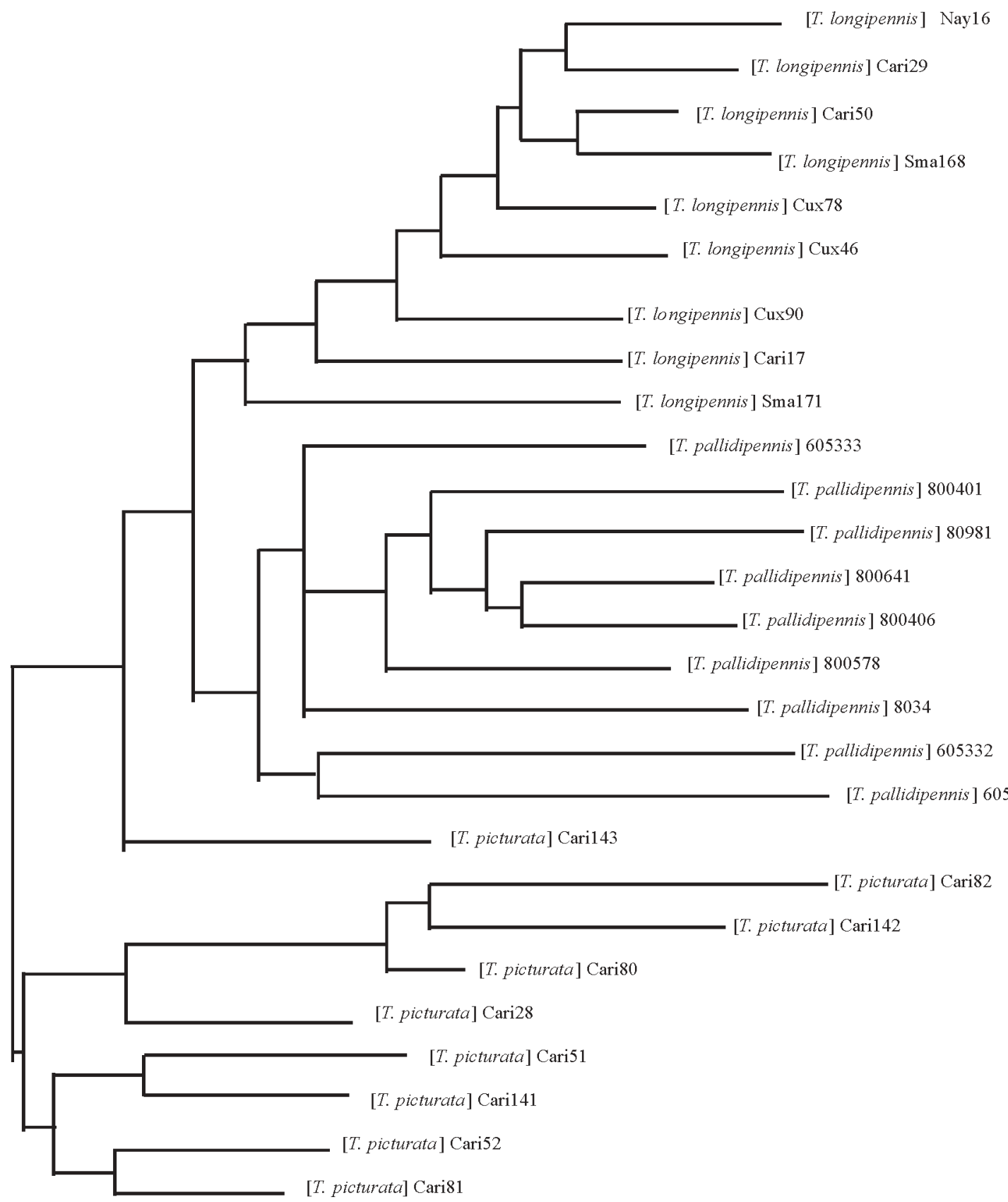

Fig. 2: a Neighbor Joining tree derived from Sneath and Sokal genetic distances between the 27 triatomine samples of three phyllosoma complex species analyzed by random amplification of polymorphic DNA and characterized by the presence/absence of 53 bands 


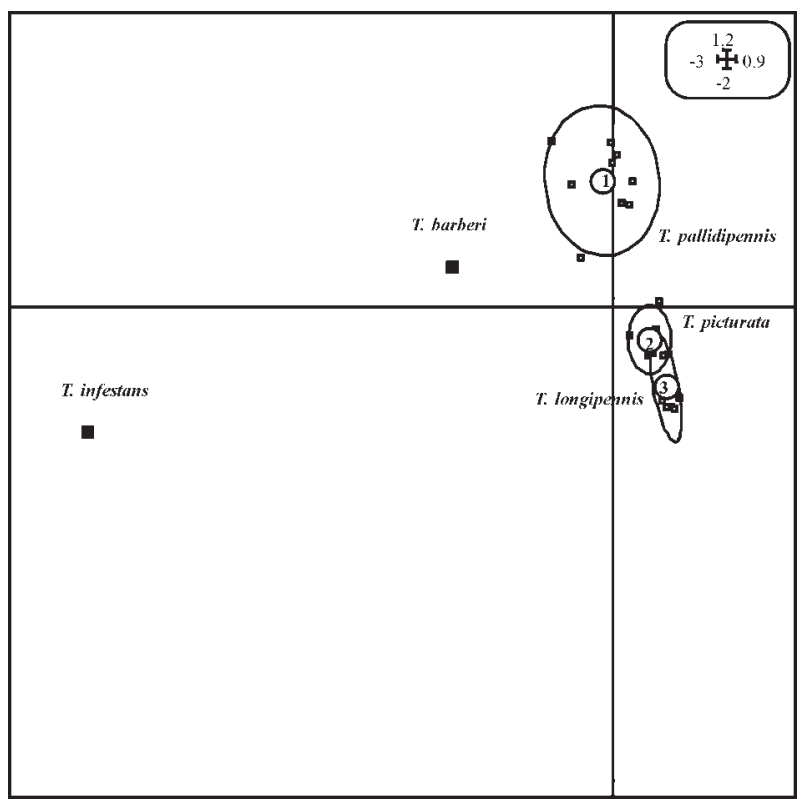

Fig. 3: multiple correspondence analysis of the 29 triatomine samples analyzed by random amplification of polymorphic DNA. The ADE4 ellipses option computes the means, variances, and covariance of each group of points on both axes and draws a corresponding ellipse. This ellipse theoretically clusters $90 \%$ of the points belonging to the different groups chosen: $1, T$. pallidipennis; $2, T$. picturata, and $3, T$. longipennis

among the phyllosoma complex species. These morphological characteristics differentiate adults through the use of taxonomic keys, even when these species are sympatric, as in the case of $T$. longipennis and T. picturata in Nayarit (Magallón-Gastéllum et al. 2001). Hence, adult morphological characteristics appear to be stable parameters for individual species and for differentiation between species, even when species' sympatry provides the potential for hybrid individuals. Although Mazzotti and Osorio (1942) noted the production of F1 individuals from four crosses of phyllosoma complex species with certain characteristics of both parents, they never indicated the percentage of these among the normal morphotypes produced. In addition, although they noted F2 nymph development from hybrid F1 littermate crosses, they never reported viable adult development from these individuals, and never attempted backcrosses. Unfortunately, they never attempted hybrids of $T$. longipennis and T. picturata.

Although RAPD and other molecular markers are capable of differentiating between most species of the complex, at least in the case of T. longipennis and T. picturata it is more difficult. Analysis of mitochondrial DNA may be more appropriated to differentiating closely related species as shown among other members of the Triatominae (Monteiro et al. 1999).

\section{ACKNOWLEDGMENT}

To A Cordeiro da Silva, University of Porto, for collaboration and the ERASMUS program for trainning.

\section{REFERENCES}

Bargues MD, Marcilla A, Ramsey JM, Dujardin JP, Schofield CJ, Mas-Coma S 2000. Nuclear rDNA-based molecular clock of the evolution of triatominae (Hemiptera: Reduviidae), vectors of Chagas disease. Mem Inst Oswaldo Cruz 95: 567-573.

Flores A, Magallón Gastélum E, Bosseno MF, Ordoñez R, Lozano Kasten F, Espinoza B, Ramsey J, Brenière SF 2001. Isoenzyme variability of five principal triatomine vector species of Chagas disease in Mexico. Infec Genet Evol 1: 21-28.

Galvão C, Carcavallo R, Silva Rocha D, Jurberg J 2003. A checklist of the current valid species of Triatominae Jeannel, 1919 (Hemiptera, Reduviidae) and their geographical distribution, with nomenclature and taxonomic notes. Zootaxa 202: 1-36.

Garcia AL, Carrasco HJ, Schofield CJ, Stothard JR, Frame IA, Valente SA, Miles MA 1998. Random amplification of polymorphic DNA as a tool for taxonomic studies of triatomine bugs (Hemiptera: Reduviidae). J Med Entomol 35: 38-45.

Guzmán-Bracho C 2001. Epidemiology of Chagas disease in Mexico: an update. Trends Parasitol 17: 372-376.

Harris K 2001. Taxonomy and Phylogeny of the North American Triatominae: Public Health Implications, PhD Thesis, Moorhouse School of Medicine, US.

Lent H, Wygodzinsky P 1979. Revision of the Triatominae (Hemiptera, Reduviidae) and their significance as vectors of Chagas'disease. Bull Am Mus Nat Hist 163: 123-520.

Magallón-Gastélum E, Lozano-Kasten F, Flores-Perez A, Bosseno MF, Brenière SF 2001. Sylvatic Triatominae of the phyllosoma complex (Hemiptera: Reduviidae) around the community of Carrillo Puerto, Nayarit, Mexico. J Med Entomol 38: 638-640.

Marcilla A, Bargues MD, Ramsey JM, Magallón-Gastélum E, Salazar-Schettino PM, Abad-Franch F, Dujardin JP, Schofield CJ, Mas-Coma S 2001. The ITS-2 of the nuclear rDNA as a molecular marker for populations, species, and phylogenetic relationships in Triatominae (Hemiptera: Reduviidae), vectors of Chagas disease. Mol Phylogenet Evol 18: 136-142.

Mazzotti L, Osorio MT 1942. Cruzamientos experimentales entre varias especies de triatomas. Rev Mex Med 22: 215222.

Monteiro FA, Perez R, Panzera F, Dujardin JP, Galvão C, Rocha D, Noireau F, Schofield C, Beard CB 1999. Mitochondrial DNA variation of Triatoma infestans populations and its implication on the specific status of T. melanosoma. Mem Inst Oswaldo Cruz 94: 229-238

Ramsey JM, Ordonez R, Cruz-Celis A, Alvear AL, Chavez V, Lopez R, Pintor JR, Gama F, Carrillo S 2000. Distribution of domestic triatominae and stratification of Chagas disease transmission in Oaxaca, Mexico. Med Vet Entomol 14: 19-30.

Ryckman RE 1962. Biosystematics and hosts of the Triatoma protracta complex in North America (Hemiptera: Reduviidae) (Rodentia:Cricetidae). Univ Calif Publ Entomol 27: 93-240.

Thioulouse J, Chessel D, Dolédec S, Olivier JM 1997. ADE-4: a multivariate analysis and graphical display software. Statistics and Computing 7: 75-83.

Velasco-Castrejón O, Guzmán-Bracho C 1986. Importancia de la enfermedad de Chagas en México. Rev Latinoam Microbiol 28: 275-283.

Zárate LJ, Zárate RJ 1985. A checklist of the Triatominae (Hemiptera, Reduviidae) of Mexico. Int J Entomol 61: 257-271. 